\title{
Knowledge, Attitude and Practice on Various Local Anesthesia Techniques for Maxillary Teeth Extractions Among Dental Students
}

\author{
Vishnu Prasanna S.G. ${ }^{1}$ and Dinesh Prabu.M² \\ ${ }^{1}$ Saveetha Dental College and Hospitals, Saveetha Institute of Medical \\ and Technical Science (SIMATS), Saveetha University, Chennai,India \\ ${ }^{2}$ Senior Lecturer, Department of Oral and Maxillofacial Surgery, Saveetha Dental College and Hospitals, \\ Saveetha Institute Of Medical and Technical Science (SIMATS), Saveetha University, Chennai,India
}

\section{ABSTRACT}

Local anesthetic agents block the peripheral nerves and prevent the conduction of pain perception, making the treatment procedure easy and comfortable. Lidocaine is the most commonly used drug for induction of local anesthesia. Maxillary teeth extractions usually require up to five injections to obtain anesthesia of the hard and soft tissues. The Posterior superior alveolar, middle superior alveolar and anterior superior alveolar, greater palatine and nasopalatine blocks are used for anesthetizing the maxillary teeth. The study aims at assessing the knowledge and awareness of various local anesthetic techniques for maxillary teeth extractions. A questionnaire based survey was conducted in January 2020 among dental students. 150 dental students working in a private dental college and hospital participated in this study. The questionnaire consisted of 16 questions related to various local anesthetic techniques. The collected data was added in MS Excel and subjected to statistical analysis using SPSS software and Chi-square test was done. The results depicted that 28.67\% of interns, $12 \%$ final years and $2 \%$ of third years were aware of the various local anesthesia techniques for maxillary teeth extractions. $27.33 \%$ of interns, $16.67 \%$ of final years and 22\% of third years preferred infiltration for maxillary teeth extractions whereas $11.33 \%$ of third years, $16.67 \%$ of final years and $12.67 \%$ of interns preferred nerve block techniques. 30\% of interns and $26.67 \%$ of third years felt that nerve block is technique sensitive for maxillary teeth extractions. Within the limitation of the study it was seen that Interns had a good knowledge, attitude and practice on various local anesthesia techniques for maxillary teeth extractions when compared to the final and third years.

\section{KEY WORDS: ANAESTHESIA; INFILTRATION; MAXILLARY TEETH; NERVE BLOCK.}

\section{INTRODUCTION}

The most important skill required of all dental practitioners is the ability to provide safe and effective local anesthesia

\section{ARTICLE INFORMATION}

*Corresponding Author: dineshprabum.sdc@saveetha.com Received 11th June 2020 Accepted after revision 10th August 2020 Print ISSN: 0974-6455 Online ISSN: 2321-4007 CODEN: BBRCBA

Thomson Reuters ISI Web of Science Clarivate Analytics USA and Crossref Indexed Journal

\section{1) Clarivate}

NAAS Journal Score 2020 (4.31) SJIF: 2020 (7.728)

A Society of Science and Nature Publication,

Bhopal India 2020. All rights reserved.

Online Contents Available at: http//www.bbrc.in/

Doi: $h t t p: / / d x . d o i . o r g / 10.21786 / b b r c / 13.7 / 31$
(Saxena et al., 2013). Local anesthetic agents block the peripheral nerves and prevent the conduction of pain perception, making the patient and the dentist more comfortable (Parirokh and Abbott, 2014). The injection of local anesthetic is perhaps the greatest source of patient fear (Milgrom, Weinstein and Getz, 1995) (AL-Omari and AL-Omiri, 2009) and inability to obtain adequate pain control with minimal discomfort remains a significant concern of dental practitioners (Kaufman, Weinstein and Milgrom, 1984). Pain and anxiety related to dentistry have historically been the main reason for poor attendance at the dentist (Hochman et al., 1997). The achievement of good local anesthesia requires the following: knowledge 
of the agents being used, the neuroanatomy involved, and the best techniques and devices available.

The advancements in various agents and anesthetic delivery equipment available provide the practitioner with an array of options to effectively manage the pain caused during dental procedures. Lidocaine is the most commonly used drug for induction of local anesthesia. It is an amide anesthetic agent with a shorter duration and rapid action ; the effect of Lidocaine increases when used with association with adrenaline (Becker and Reed, 2012). Articaine is an anesthetic agent belonging to the amide family and is said to be more soluble in lipids when compared to Lidocaine which is due to the presence of a thiophene ring in its chemical structure which helps easy penetration into the lipid membrane of nerves (Leith, Lynch and 0'Connell, 2012). Articaine has strong affinity for proteins, hence penetrates into bone (Gusi, Raimundo and Leal, 2006)

Maxillary teeth are anesthetized by administering a local anesthetic injection in the mucobuccal supraperiosteal fold in the proximity to the apices of teeth to be anesthetized. Maxillary teeth extractions usually require up to five injections to obtain anesthesia of the hard and soft tissues. The Posterior superior alveolar, middle superior alveolar and anterior superior alveolar nerve block injections, greater palatine and nasopalatine blocks are used to anesthetize the maxillary teeth. A bilateral Anterior middle superior alveolar injection anesthetizes 10 maxillary teeth extending from the second premolar of one side to the second premolar on the opposite side (Friedman and Hochman, 1999). The AMSA injection derives its name from the injection's ability to supposedly anesthetize both the anterior and middle superior alveolar nerves (Sf., 1997). The anterior superior alveolar and middle superior alveolar nerves branch from the infraorbital nerve before they exit from the infraorbital foramen.

Currently there are many advancements in delivering local anasthesia to maxillary teeth for various dental procedures. The maxillary teeth can also be anesthetized with troncular techniques or intraligamentary and intraosseous injection. Recent studies prove that only the buccal infiltration with articaine can be used which has the potential to anaesthetise all dental tissues for various dental procedures.

With a rich case bank established over 3 decades we have been able to publish extensively in our domain (Abdul Wahab et al., 2017; Eapen, Baig and Avinash, 2017; Patil et al., 2017; Jain and Nazar, 2018; J et al., 2018; Marimuthu et al., 2018; Wahab et al., 2018; Abhinav et al., 2019; Ramadorai, Ravi and Narayanan, 2019; Senthil Kumar et al., 2019; Sweta, Abhinav and Ramesh, 2019). Based on this inspiration we aim to assess the Knowledge, attitude and practice on various local anesthesia techniques for maxillary teeth extractions among dental students.

\section{MATERIAL AND METHODS}

Study design: Awareness based survey

Data collection: A survey was conducted in January 2020 among dental students (Third years, Final years, Interns). It was an online questionnaire based study, conducted to assess the Knowledge, attitude and practice on various local anesthesia techniques for maxillary teeth extractions. 150 dental students (Third years, Final years, Interns) participated in this study. The data collection was done via google forms.

Survey instrument: A pretested, self administered, closed ended questionnaire comprising the following sections formed the survey instrument. A structured questionnaire containing 10 questions which was adopted from a validated questionnaire developed by the World Health Organisation. The questionnaire was equally distributed among Third years, Final years, Interns. The goal of developing this questionnaire was to know about the Knowledge, attitude and practice on various local anesthesia techniques for maxillary teeth extractions. The questions had to be answered with a Yes or No response.

Ethical approval: Ethical approval was attained from the Institutional Ethical Committee.

Data analysis: The data collected was entered in an Excel sheet and subjected to statistical analysis using SPSS version 20. Chi square test was done. The independent variables are age and gender while dependent variables are knowledge, attitude and practice on various local anesthesia techniques for maxillary teeth extractions. The level of significance was set at $\mathrm{p}<0.05$.

\section{Questionnaire given is as follows:}

1. Are you aware of various local anesthesia techniques for maxillary teeth extraction?

2. Do you always prefer infiltration for maxillary teeth extraction?

3. Do you always prefer nerve block for maxillary teeth extraction?

4. Do you think that nerve block is technique sensitive for maxillary arch?

5. Are you aware of the complications of nerve block?

6. Have you faced any complications after giving nerve block?

7. Do you feel that infiltration is better than nerve block?

8. Do you feel that nerve block has a better anesthetic effect than infiltration?

9. Do you think that local anesthesia produces post extraction discomfort?

10. Do you think that more programs should be conducted on local anesthesia techniques for maxillary teeth extraction?

11. Are you aware of the evolutionary painless injection? 
12. Do you know about the cartridge type of injections?

13. Do you know the each nerve supply of each root of the maxillary molars?

14. Do you know the methods to make palatal infiltrations painless?

15. Do you know how a hematoma is caused?

16. Do you prefer longer acting anesthetic agents like articaine

Figure 1: Bar graph denotes association between year of study of the participants and number of participants who were aware of various local anesthesia techniques for maxillary teeth extraction. $\mathrm{X}$ axis denotes the year of study of the participants and $\mathrm{Y}$ axis denotes the number of responses. The response of yes (green) was mostly given by the interns and the majority of the third years have given a response of no (blue). Chi square test shows $p=0.000$, significant. Hence proving that there is significant association between the year of study of the participants and the number of dental students who were aware of various local anesthesia techniques for maxillary teeth extraction.

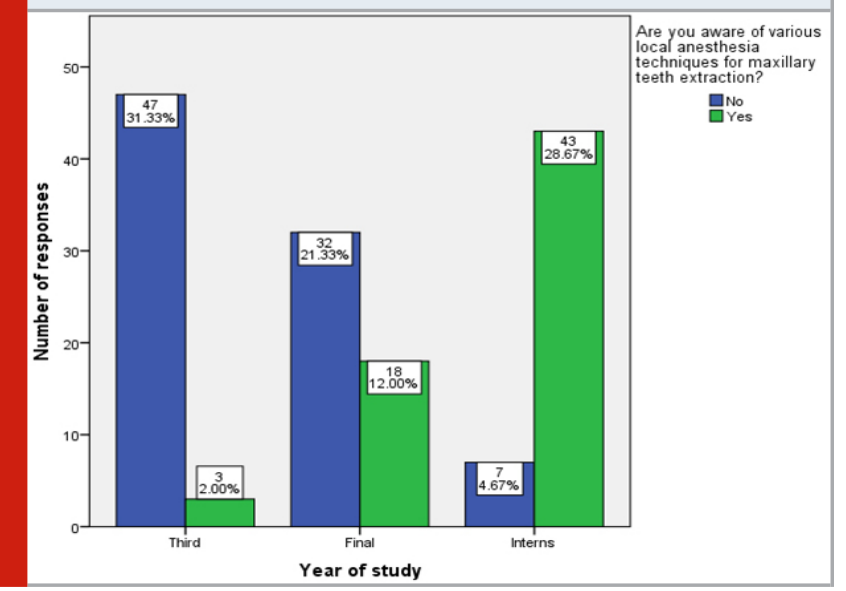

\section{RESULTS AND DISCUSSION}

From the results of the study, it was seen that $28.67 \%$ of interns, 12\% final years and $2 \%$ of third years were aware of the various local anesthesia techniques for maxillary teeth extractions Chi square test shows $\mathrm{p}$ value $=0.00$ (Figure 1). $27.33 \%$ of interns, $16.67 \%$ of final years and $22 \%$ of third years preferred infiltration for maxillary teeth extractions Chi square test shows $p$ value $=0.00$ (Figure 2 ) whereas $11.33 \%$ of third years, $16.67 \%$ of final years and $12.67 \%$ of interns preferred nerve block techniques Chi square test shows $\mathrm{p}$ value $=0.00$ (Figure 3). 30\% of interns and $26.67 \%$ of third years felt that nerve block is technique sensitive for maxillary teeth extractions Chi square test shows $p$ value $=0.00$ (Figure 4). 31.33\% of interns, 14\% of final years and $8 \%$ of third years were aware of complications of nerve block Chi square test shows $p$ value $=0.00$ (Figure 5). $30.67 \%$ of third years, $30.67 \%$ of final years and $21.33 \%$ of interns have never faced any complications after

delivering nerve block Chi square test shows $\mathrm{p}$ value $=0.00$ (Figure 6). 30\% of third years, 25.33\% of final years and 28\% of interns felt that infiltration is better than nerve block Chi square test shows $p$ value $=0.00$ (Figure 7). 22\% of third years,

Figure 2: Bar graph denotes association between year of study of the participants and number of participants who always prefer infiltration for maxillary teeth extraction. $\mathrm{X}$ axis denotes the year of study of the participants and $\mathrm{Y}$ axis denotes the number of responses. The response of yes (green) was mostly given by the interns and the majority of the final years have given a response of no (blue). Chi square test shows $\mathrm{p}=\mathbf{0 . 0 0 0}$, significant. Hence proving that there is significant association between the year of study of the participants and the number of dental students who always prefer infiltration for maxillary teeth extraction.

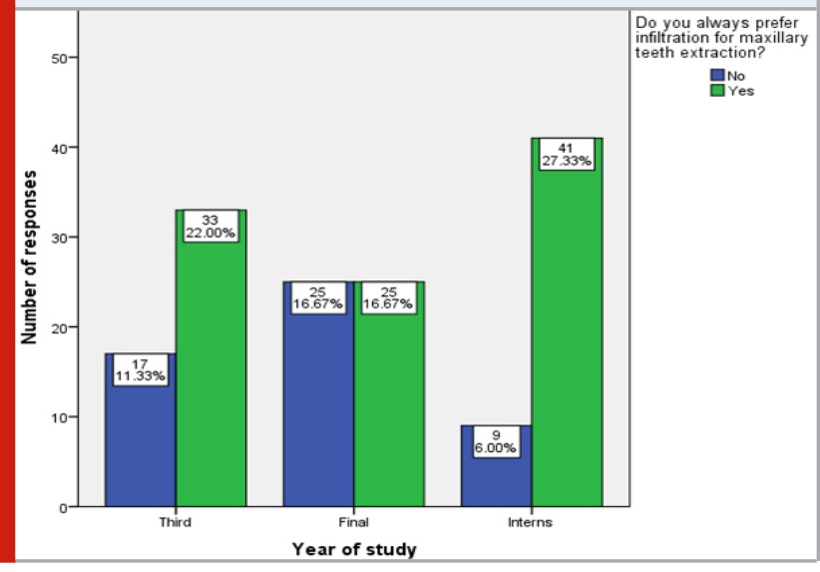

Figure 3: Bar graph denotes association between year of study of the participants and number of participants who always prefer nerve blocks for maxillary teeth extraction. $\mathrm{X}$ axis denotes the year of study of the participants and $\mathrm{Y}$ axis denotes the number of responses. The response of yes (green) was mostly given by the final years and the majority of the third years have given a response of no (blue). Chi square test shows $\mathrm{p}=\mathbf{0 . 0 0 0}$, significant. Hence proving that there is significant association between the year of study of the participants and the number of dental students who always prefer nerve blocks for maxillary teeth extraction.

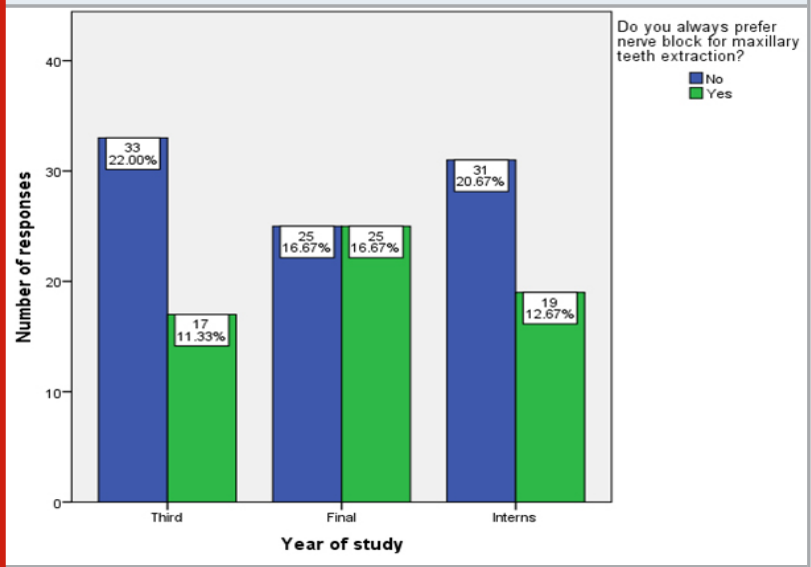


Figure 4: Bar graph denotes association between year of study of the participants and number of participants who thought that nerve block is technique sensitive for maxillary arch. $\mathrm{X}$ axis denotes the year of study of the participants and $\mathrm{Y}$ axis denotes the number of responses. The response of yes (green) was mostly given by the interns and the majority of the final years have given a response of no (blue). Chi square test shows $\mathrm{p}=0.000$, significant. Hence proving that there is significant association between the year of study of the participants and the number of dental students who thought that nerve block is technique sensitive for maxillary arch.

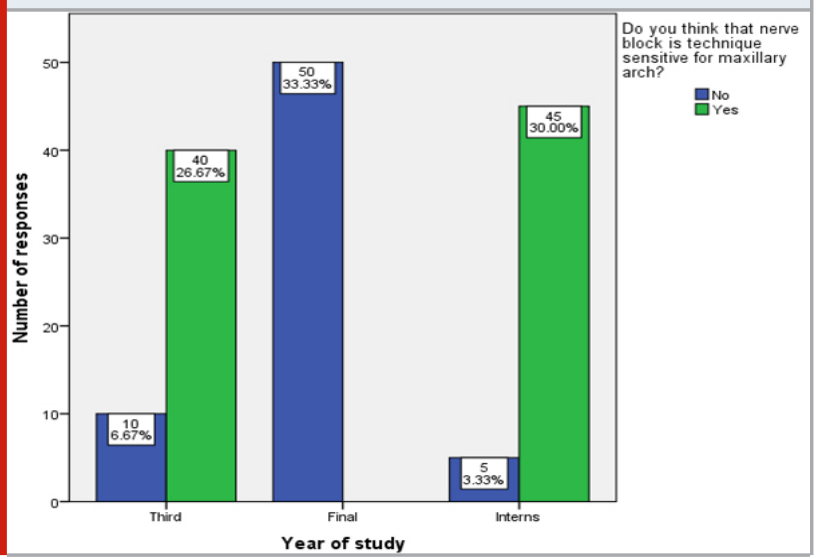

Figure 5: Bar graph denotes association between year of study of the participants and number of participants who were aware of complications of nerve block. $\mathrm{X}$ axis denotes the year of study of the participants and $\mathrm{Y}$ axis denotes the number of responses. The response of yes (green) was mostly given by the interns and the majority of the third years have given a response of no (blue). Chi square test shows $\mathrm{p}=0.000$, significant. Hence proving that there is significant association between the year of study of the participants and the number of dental students who were aware of complications of nerve block.

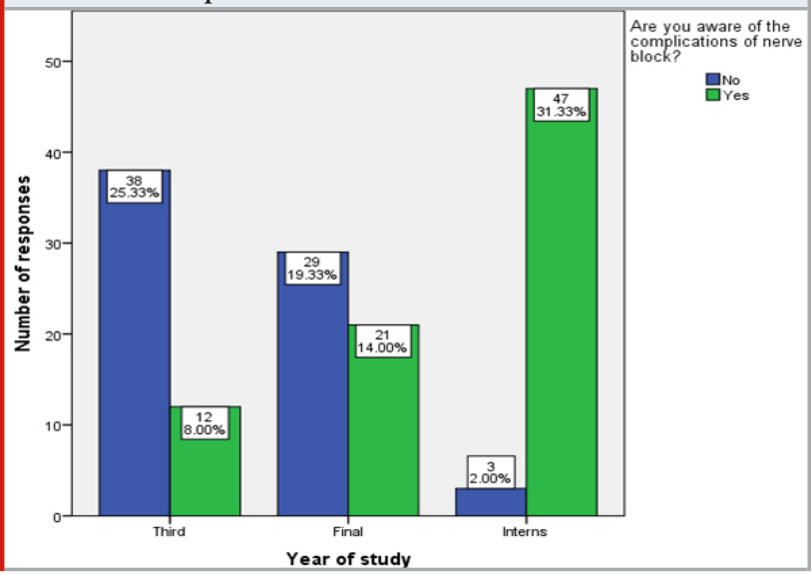

$27.33 \%$ of final years and $27.33 \%$ of interns felt that nerve block had better anesthetic effect Chi square test shows p value $=0.00$ (Figure 8). 24.67\% of third years, $26 \%$ of final years and $31.33 \%$ of interns felt that anesthesia produces post extraction discomfort
Chi square test shows p value $=0.00$ (Figure 9). 32\% of third years, $28.67 \%$ of final years and $20.67 \%$ of interns felt that more programs should be conducted on local anesthesia techniques Chi square test shows $p$ value $=0.00$ (Figure 10). 28\% of third years, 29.33\% of final years and $20 \%$ of interns were not aware of painless injections Chi square test shows p value $=0.00$ (Figure 11). 32\% of third years, 18.67 of final years and 3.33\% of interns did not know about the cartridge type of injections Chi square test shows $\mathrm{p}$ value $=0.00$ (Figure 12).

Figure 6: Bar graph denotes association between year of study of the participants and number of participants who faced complications after a nerve block. $\mathrm{X}$ axis denotes the year of study of the participants and $\mathrm{Y}$ axis denotes the number of responses. The response of yes (green) was mostly given by the interns and the majority of the third years and interns have given a response of no (blue). Chi square test shows $\mathrm{p}=\mathbf{0 . 0 0 0}$, significant. Hence proving that there is significant association between the year of study of the participants and the number of dental students who were aware of complications of nerve block.

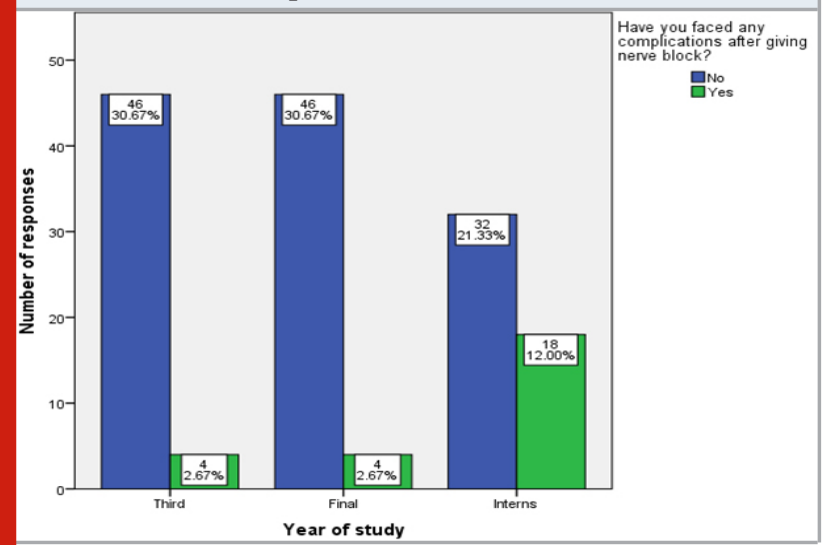

Figure 7: Bar graph denotes association between year of study of the participants and number of participants who felt infiltration was better than a nerve block. $X$ axis denotes the year of study of the participants and $Y$ axis denotes the number of responses. The response of yes (green) was mostly given by the third years and the response of no (blue) was mostly given by final years. Chi square test shows $\mathrm{p}=\mathbf{0 . 0 0 0}$, significant. Hence proving that there is significant association between the year of study of the participants and the number of dental students who felt infiltration was better than a nerve block.

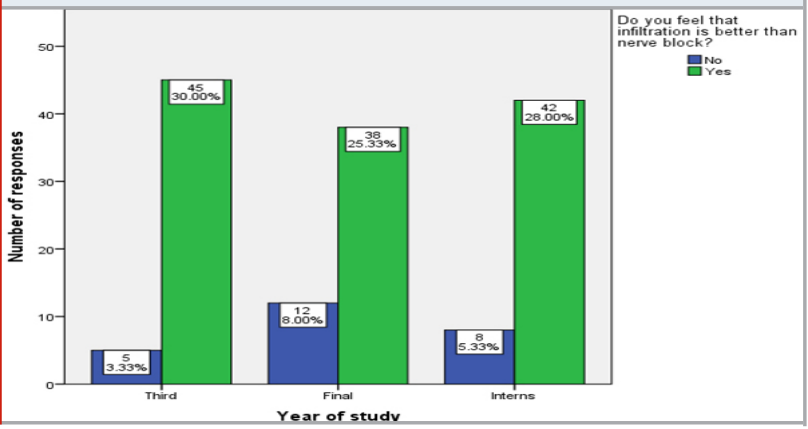


Figure 8: Bar graph denotes association between year of study of the participants and number of participants who thought that nerve block has better anesthetic effect than infiltration. $X$ axis denotes the year of study of the participants and $\mathrm{Y}$ axis denotes the number of responses. The response of yes (green) was mostly given by the interns and final years and the response of no (blue) was mostly given by the third years. Chi square test shows $\mathrm{p}=0.000$, significant. Hence proving that there is significant association between the year of study of the participants and the number of dental students who thought that nerve block has better anesthetic effect than infiltration.

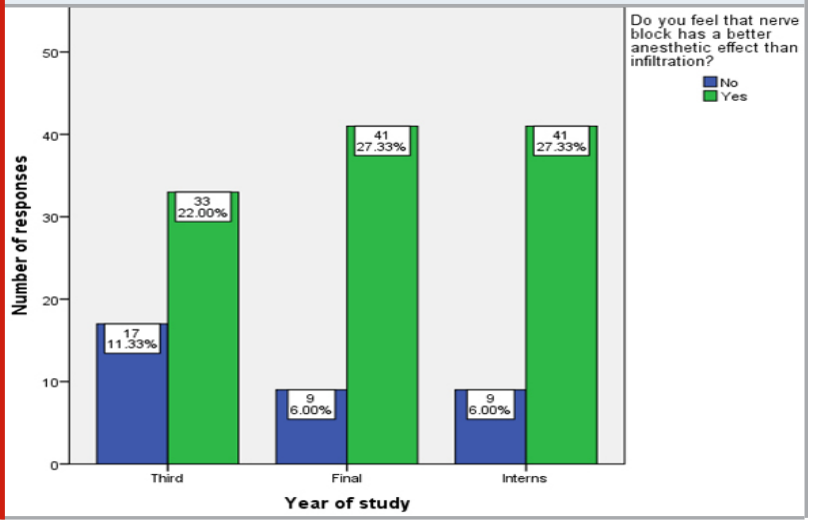

Figure 9: Bar graph denotes association between year of study of the participants and number of participants who thought that local anaesthesia produces post extraction discomfort. $\mathrm{X}$ axis denotes the year of study of the participants and $\mathrm{Y}$ axis denotes the number of responses. Majority of interns gave a response of yes (green) and the response of no (blue) was mostly given by the third years. Chi square test shows $\mathrm{p}=0.000$, significant. Hence proving that there is significant association between the year of study of the participants and the number of dental students who thought that local anaesthesia produces post extraction discomfort.

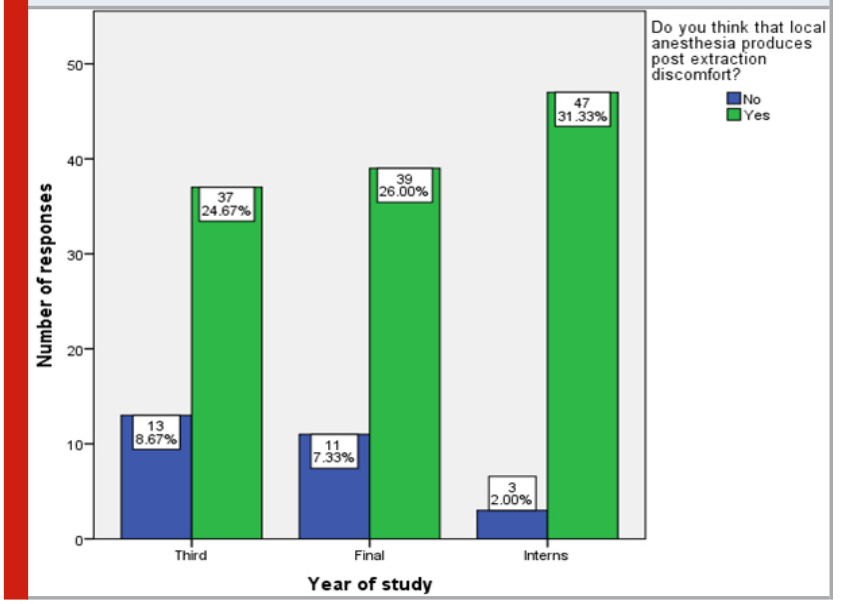

$24.67 \%$ of third years, $24.67 \%$ of final years and 30\% of interns knew the nerve supply of each root of maxillary molars Chi square test shows $p$ value $=0.00$ (Figure 13).

$32 \%$ of third years, $27.33 \%$ of final years and $16.67 \%$ of interns did not know the methods to make palatal infiltration painless Chi square test shows $p$ value $=0.00$ (Figure 14). 8\% of third years, 29.33\% of final years and $31.33 \%$ of interns knew how hematoma was caused. Chi square test shows $\mathrm{p}$ value $=0.00$ (Figure 15). 30.67\% of third years, $28.67 \%$ of final years and $26.67 \%$ of interns did not prefer longer acting anesthetic agents Chi square test shows $\mathrm{p}$ value $=0.00$ (Figure 16).

Figure 10:Bar graph denotes association between year of study of the participants and number of participants who thought that more programs should be conducted on local anesthesia techniques for maxillary teeth extraction. $\mathrm{X}$ axis denotes the year of study of the participants and $Y$ axis denotes the number of responses. Majority of third years gave a response of yes (green) and the response of no (blue) was mostly given by the interns. Chi square test shows $p=0.000$, significant. Hence proving that there is significant association between the year of study of the participants and the number of dental students who thought that more programs should be conducted on local anesthesia techniques for maxillary teeth extraction.

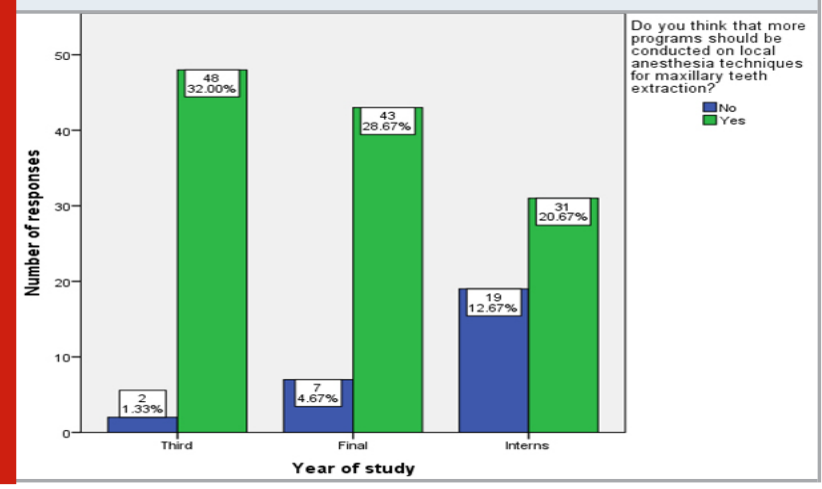

Figure 11: Bar graph denotes association between year of study of the participants and number of participants who were aware of the painless injection techniques. $\mathrm{X}$ axis denotes the year of study of the participants and Y axis denotes the number of responses. Majority of third years gave a response of no (blue) and the response of yes (green) was mostly given by the interns. Chi square test shows $\mathrm{p}=\mathbf{0 . 0 0 0}$, significant. Hence proving that there is significant association between the year of study of the participants and the number of dental students who were aware of the painless injection techniques.

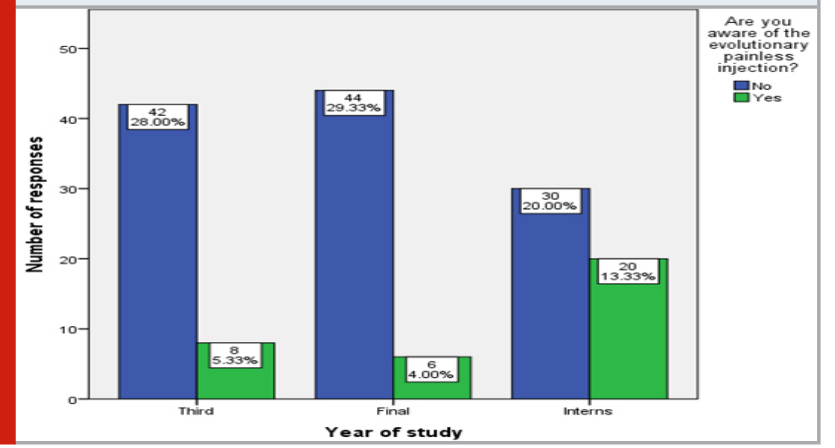


Figure 12: Bar graph denotes association between year of study of the participants and number of participants who had known about cartridge type of injections. $\mathrm{X}$ axis denotes the year of study of the participants and $\mathrm{Y}$ axis denotes the number of responses. The response of yes (green) was mostly given by the interns and the majority of the third and final years have given a response of no (blue). Chi square test shows $\mathrm{p}=0.000$, significant. Hence proving that there is significant association between the year of study of the participants and the number of dental students who know about cartridge type of injection.

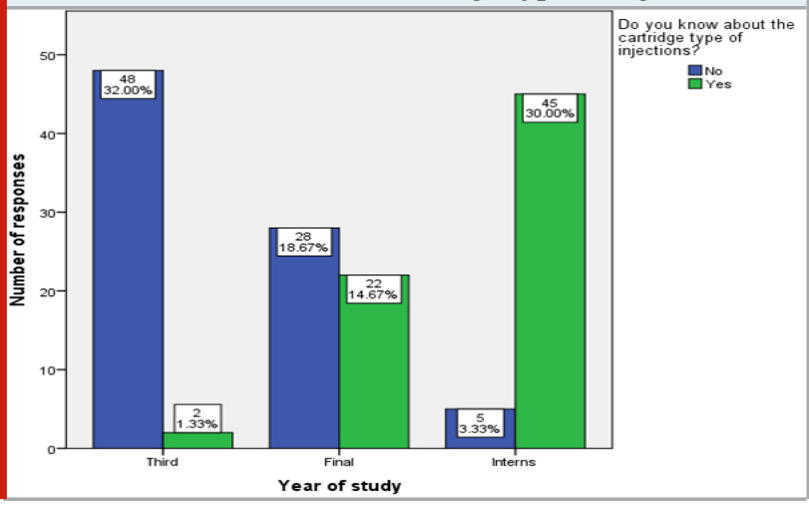

Figure 13: Bar graph denotes association between year of study of the participants and number of participants who had known about the each nerve supply of each root of maxillary molars. $X$ axis denotes the year of study of the participants and $\mathrm{Y}$ axis denotes the number of participants. The response of yes (green) was mostly given by the third years, final years and interns when compared to No (blue). Chi square test shows $\mathrm{p}=0.000$, significant. Hence proving that there is significant association between the year of study of the participants and the number of dental students who had known about each nerve supply of each root of maxillary molars.

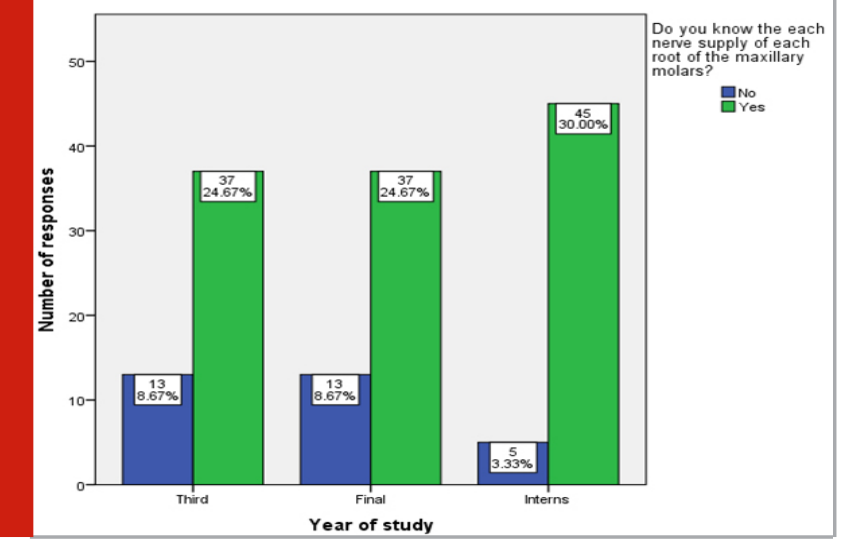

In our study, it was found that maximum number of participants preferred infiltration when compared to nerve block. Most of them felt that the nerve block in the maxillary arch was technique sensitive. Majority of the participants were aware of complications of nerve but most of them have not faced any complications till now. Most of the participants felt that infiltration than nerve block but felt that nerve block had better anesthetic effect and they felt that local anesthesia often felt that local anesthesia produces post extraction discomfort. Most of the participants wanted more programs to be conducted on techniques of local anesthesia. Most of the participants had a good knowledge on nerve supply of maxillary molars but majority of them did not know how to make palatal infiltration painless. Most of them knew how a hematoma was caused.

Figure 14: Bar graph denotes association between year of study of the participants and number of participants who had known the methods to make palatal infiltrations painless. $X$ axis denotes the year of study of the participants and $\mathrm{Y}$ axis denotes the number of participants. The response of no(blue) was mostly given by the third years and final years, Interns have given a equal response of no (blue) and yes (green). Chi square test shows $\mathrm{p}=0.000$, significant. Hence proving that there is significant association between the year of study of the participants and the number of dental students who had known the methods to make palatal infiltrations painless.

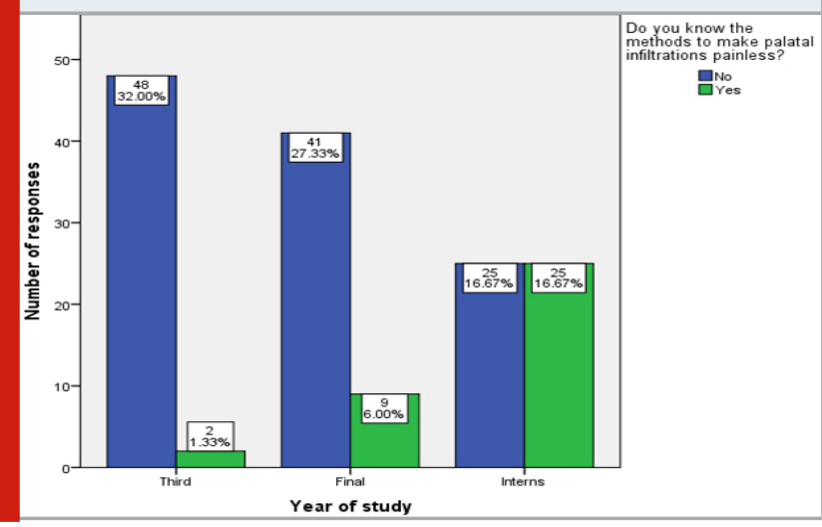

Figure 15: Bar graph denotes association between year of study of the participants and number of participants who had known how a hematoma was caused. $X$ axis denotes the year of study of the participants and $\mathrm{Y}$ axis denotes the number of participants. The response of yes (green) was mostly given by the final years and interns, the majority of the third years have given a response of no (blue). Chi square test shows $\mathrm{p}=0.000$, significant. Hence proving that there is significant association between the year of study of the participants and the number of dental students who had known how a hematoma was caused.

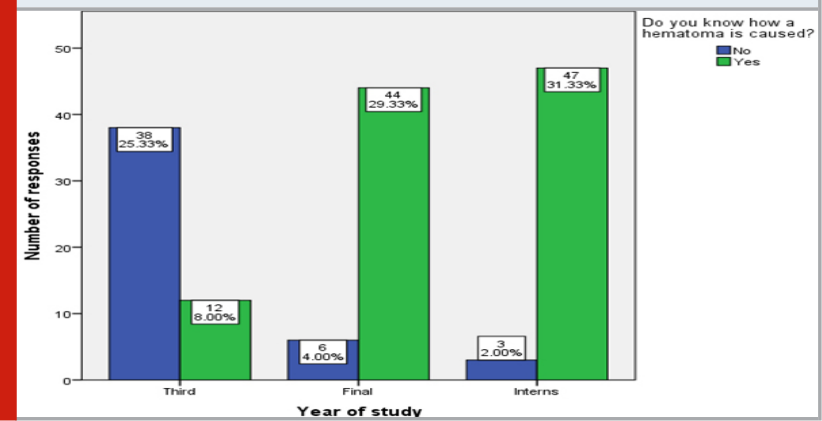


Figure 16: Bar graph denotes association between year of study of the participants and number of participants who preferred longer acting anesthetic agents. $\mathrm{X}$ axis denotes the year of study of the participants and $\mathrm{Y}$ axis denotes the number of responses. The response of yes (green) was mostly given by the interns and the majority of the third years have given a response of no (blue). Chi square test shows $\mathrm{p}=0.000$, significant. Hence proving that there is significant association between the year of study of the participants and the number of dental students who preferred longer acting anesthetic agents.

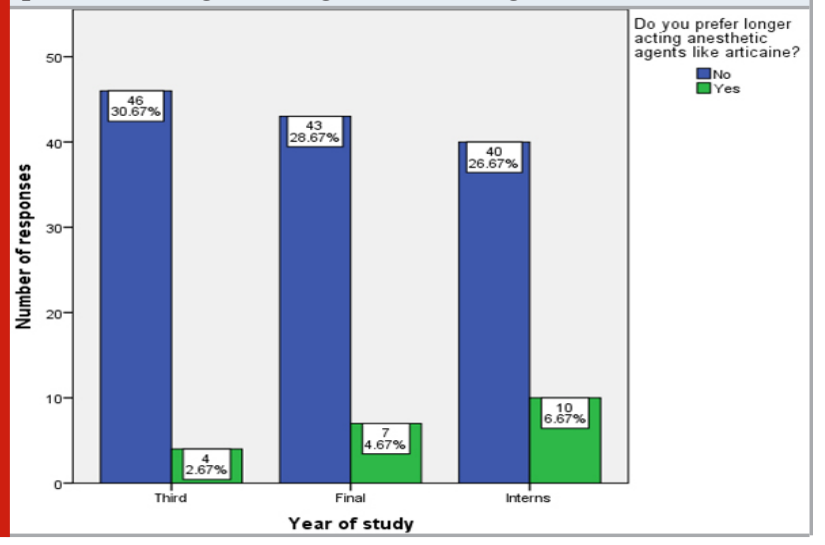

In our study, it was reported that most of them did not prefer longer acting local anesthetic agents like articaine. In contrast to our study, Ensiyeh et al. reported that infiltration of Articaine resulted in more effective anesthesia compared to Lidocaine in the PSA technique (Maljaei et al., 2017). Katya et al. reported that Articaine had higher post-injection pain compared to Lidocaine, but pain scores were negligible clinically (Katyal, 2010). Bartlett et al. reported that the success of infiltration of Articaine was almost similar to that of IANB technique with Lidocaine. Our study shows that many of the participants did not know how to make palatal injections painless (Bartlett and Mansoor, 2016). Mittal et al. reported that buccal infiltration with articaine failed to provide adequate palatal anesthesia, it can still be considered a good alternative to lidocaine for local anesthesia (Mittal et al., 2015).

The results depict that the majority of them were not aware of the various techniques of local anesthesia in maxillary teeth extractions. Amit et al. reported that most of the patients reacted well to the anterior middle superior alveolar technique. Adequate anaesthesia for an accepted duration was achieved and it reduced cumulative reduction of the number of injections reducing patient discomfort (Sangle, Tambuwala and Agrawal, 2012).

In our study, it was reported that the majority of the participants were not aware of various advanced techniques for delivering local anesthesia like cartridge type of injections. Kandiah et al. reported that there was no difference in the onset of local anaesthesia or pain difference when using the Wand and conventional technique when administering buccal infiltration (Kandiah and Tahmassebi, 2012).

\section{CONCLUSION}

Within the limitation of the study it was seen that Interns had a good Knowledge, attitude and practice on various local anesthesia techniques for maxillary teeth extractions when compared to the final and third years. This is because of the clinical expertise that the interns have acquired through clinical experience and clinical practice.

\section{ACKNOWLEDGEMENTS}

The authors acknowledge all the parents who provided consent and spent their time on completing this survey.

Conflicts of Interest: The authors of the study declare that there were no conflicts of interest.

\section{REFERENCES}

Abdul Wahab, P. U. et al. (2017) 'Risk Factors for Postoperative Infection Following Single Piece Osteotomy', Journal of maxillofacial and oral surgery, 16(3), pp. 328-332.

Abhinav, R. P. et al. (2019) 'The Patterns and Etiology of Maxillofacial Trauma in South India', Annals of maxillofacial surgery, 9(1), pp. 114-117.

AL-Omari, W. M. and AL-Omiri, M. K. (2009) 'Dental anxiety among university students and its correlation with their field of study', Journal of Applied Oral Science, pp. 199-203. doi: 10.1590/s167877572009000300013.

Bartlett, G. and Mansoor, J. (2016) 'Articaine buccal infiltration vs lidocaine inferior dental block - a review of the literature', British Dental Journal, pp. 117-120. doi: 10.1038/sj.bdj.2016.93.

Becker, D. E. and Reed, K. L. (2012) 'Local Anesthetics: Review of Pharmacological Considerations', Anesthesia Progress, pp. 90-102. doi: 10.2344/0003-300659.2.90.

Eapen, B. V., Baig, M. F. and Avinash, S. (2017) 'An Assessment of the Incidence of Prolonged Postoperative Bleeding After Dental Extraction Among Patients on Uninterrupted Low Dose Aspirin Therapy and to Evaluate the Need to Stop Such Medication Prior to Dental Extractions', Journal of maxillofacial and oral surgery, 16(1), pp. 48-52.

Friedman, M. J. and Hochman, M. N. (1999) 'P-ASA Block Injection: A New Palatal Technique to Anesthetize Maxillary Anterior Teeth', Journal of Esthetic and Restorative Dentistry, pp. 63-71. doi: 10.1111/j.17088240.1999.tb00380.x.

Gusi, N., Raimundo, A. and Leal, A. (2006) 'Lowfrequency vibratory exercise reduces the risk of bone fracture more than walking: a randomized controlled trial', BMC musculoskeletal disorders, 7, p. 92. 
Hochman, M. et al. (1997) 'Computerized local anesthetic delivery vs. traditional syringe technique. Subjective pain response', The New York state dental journal, 63(7), pp. 24-29.

Jain, M. and Nazar, N. (2018) 'Comparative Evaluation of the Efficacy of Intraligamentary and Supraperiosteal Injections in the Extraction of Maxillary Teeth: A Randomized Controlled Clinical Trial', The journal of contemporary dental practice, 19(9), pp. 1117-1121.

J, P. C. et al. (2018) 'Prevalence and measurement of anterior loop of the mandibular canal using CBCT: A cross sectional study', Clinical implant dentistry and related research, 20(4), pp. 531-534.

Kandiah, P. and Tahmassebi, J. F. (2012) 'Comparing the onset of maxillary infiltration local anaesthesia and pain experience using the conventional technique vs. the Wand in children', British dental journal, 213(9), pp. E15-E15.

Katyal, V. (2010) 'The efficacy and safety of articaine versus lignocaine in dental treatments: A metaanalysis', Journal of Dentistry, pp. 307-317. doi: 10.1016/j.jdent.2009.12.003.

Kaufman, E., Weinstein, P. and Milgrom, P. (1984) 'Difficulties in achieving local anesthesia', The Journal of the American Dental Association, pp. 205-208. doi: 10.14219/jada.archive.1984.0470.

Leith, R., Lynch, K. and O'Connell, A. C. (2012) 'Articaine use in children: A review', European Archives of Paediatric Dentistry, pp. 293-296. doi: 10.1007/ bf03320829.

Maljaei, E. et al. (2017) 'The efficacy of buccal infiltration of $4 \%$ articaine and PSA injection of 2\% lidocaine on anesthesia of maxillary second molars', Iranian endodontic journal. Iranian Center for Endodontic Research, 12(3), p. 276.

Marimuthu, M. et al. (2018) 'Canonical Wnt pathway gene expression and their clinical correlation in oral squamous cell carcinoma', Indian journal of dental research: official publication of Indian Society for Dental Research, 29(3), pp. 291-297.

Milgrom, P., Weinstein, P. and Getz, T. (1995) Treating Fearful Dental Patients: A Patient Management
Handbook.

Mittal, M. et al. (2015) 'Comparison of Anesthetic Efficacy of Articaine and Lidocaine During Primary Maxillary Molar Extractions in Children', Pediatric dentistry, 37(7), pp. 520-524.

Parirokh, M. and Abbott, P. V. (2014) 'Various strategies for pain-free root canal treatment', Iranian endodontic journal. ncbi.nlm.nih.gov. Available at: https://www. ncbi.nlm.nih.gov/pmc/articles/pmc3881296/.

Patil, S. B. et al. (2017) 'Comparison of Extended Nasolabial Flap Versus Buccal Fat Pad Graft in the Surgical Management of Oral Submucous Fibrosis: A Prospective Pilot Study', Journal of maxillofacial and oral surgery, 16(3), pp. 312-321.

Ramadorai, A., Ravi, P. and Narayanan, V. (2019) 'Rhinocerebral Mucormycosis: A Prospective Analysis of an Effective Treatment Protocol', Annals of maxillofacial surgery, 9(1), pp. 192-196.

Sangle, A., Tambuwala, A. and Agrawal, R. (2012) 'AMSA (anterior middle superior alveolar): Alternate to multiple infiltrations in maxillary anaesthesia', International Dental Journal of Students Research. International Dental Journal of Students Research, 1, pp. 42-47.

Saxena, P. et al. (2013) 'Advances in dental local anesthesia techniques and devices: An update', National journal of maxillofacial surgery, 4(1), pp. 19-24.

Senthil Kumar, M. S. et al. (2019) 'Inflammatory pseudotumour of the maxillary sinus: clinicopathological report', Oral Surgery, 12(3), pp. 255-259.

Sf., M. (1997) 'Handbook of local anesthesia', in Handbook of local anesthesia. 4th ed. St. Louis: Mosby, pp. 149, 150, 160.

Sweta, V. R., Abhinav, R. P. and Ramesh, A. (2019) 'Role of Virtual Reality in Pain Perception of Patients Following the Administration of Local Anesthesia', Annals of maxillofacial surgery, 9(1), pp. 110-113.

Wahab, P. U. A. et al. (2018) 'Scalpel Versus Diathermy in Wound Healing After Mucosal Incisions: A SplitMouth Study', Journal of oral and maxillofacial surgery: official journal of the American Association of Oral and Maxillofacial Surgeons, 76(6), pp. 1160-1164. 